\title{
A MULTIPLICIDADE DO ESPAÇO COMO REFLEXÃO DIALÉTICA
}

\author{
The Multiplicity of Space as a Dialectical Reflection
}

\author{
Claudio Manetti \\ Jonathas Magalhães Pereira da Silva
}

\section{Resumo}

O presente artigo dialoga com diversos autores na problematização da definição do Espaço e a forma de apreendermos sua dinâmica e características. Discute as formas de percepção das relações inter escalares, seu significado e as contribuições que esta reflexão é capaz de trazer para o campo da Arquitetura e do Urbanismo. Buscam-se as "chaves de conexão" da interferência antrópica como ação geomorfológica, da leitura do fragmento a inferir o espaço total. Não se aceita a normativa de insulamento de fragmentos ou recortes extraídos de certas estruturas maiores como perímetros estaques, nem se concentra nas decisões temáticas em confinamento (coerências monotemáticas), mas no cruzamento das correlações do espaço definidas pelas coerências articuladas em sistemas de troca vitais (coerências pluritemáticas). A problematização metodológica colabora com a discussão referente à critérios de delimitação das "Areas de Influência" para Estudos, Planos e Projetos, como: Estudos de Impacto Ambiental, Planos de Manejos, Planos de Intervenção Urbana e demais instrumentos de planejamento.

Palavras-Chave: Espaço. Território. Escalas. Estruturas ambientais. Estruturas socioeconômicas

http://dx.doi.org/10.11606/issn.2359-5361.v0i42p23-34

Paisag. Ambiente: Ensaios, São Paulo, n. 42, p. 23-34, jul./dez., 2018

\section{ABSTRACT}

This article makes a theoretical reflection, based on several Brazilian authors of the "field of geography", regarding the definition of Space and the way of apprehending its dynamics and physical characteristics. It discusses the forms of perception of the inter-scalar relations, their meaning and the contributions that this reflection is able to bring to the field of Architecture and Urbanism. The text searches for the "connection keys" of the anthropic interference as a geomorphological action, in order to favor the reading of the fragment and through this to infer the Total space. Therefore, the text does not adopt the regulation of insulation of fragments or cutouts extracted from certain larger structures, nor does it focus on thematic decisions in confinement (monothematic coherences). Throughout the text the arguments are constructed at the intersection of the themes of space defined by the coherences articulated in systems of vital exchange (pluri-tematic coherences). The methodological problematization collaborates with the discussion regarding the criteria in the establishment of the "Areas of Influence" for Studies, Plans and Projects, such as: Environmental Impact Studies, Management Plans, Urban Intervention Plans and other planning instruments.

Keywords: Space. Territory. Scales. Environmental structures. Social-economic structures. 


\section{INTRODUÇÃO}

O espaço pode ser compreendido por diferentes formas de observação de seu conteúdo, composto por inúmeras configurações que se interdependem em sistemas integrados por essência e correlações intercambiáveis.

Nesse sentido, coisas e seres humanos se revelam como unidades inseparáveis nas diferentes escalas de amplitude e de significância na totalidade (SANTOS, 1996). O entendimento da natureza do espaço toma como condição primordial a compreensão sobre a existência. $O$ presente texto reflete sobre alguns princípios que nos ajudem a estruturar pensamentos sobre visões interpretativas das realidades.

Para a Arquitetura e Urbanismo a dialética entre as relações do espaço e seus elementos constitutivos pode estabelecer possibilidades de inúmeras sínteses, independentemente de suas abrangências. O mesmo ocorre com as ciências voltadas para os estudos sobre a estrutura, forma e movimentos humanos na formação do planeta. A questão que nos move a refletir está no âmbito das coerências que se agrupam em determinadas escalas, que podem se mostrar por recortes ou conexões oscilantes entre indicadores da lógica operacional que subsidia e opera as razões do saber por concretas ferramentas (planos, projetos e as diversas áreas da pesquisa). A problematização metodológica busca colaborar com a discussão referente à critérios no estabelecimento das Áreas de Influência para o planejamento territorial e seus desdobramentos em dispositivos de intervenção nas diferentes escalas, e também em Estudos de Impacto Ambiental.

A proposta de pesquisar as variáveis escalares como fundamento das noções do espaço, que nos ensine a compreendê-lo mais amplamente, é um paradoxo se considerarmos a totalidade (SANTOS, 1996; WHITEHEAD, 1919; SARTRE, 1968) como corpo relacional entre "tudo que está" e "todos que são", como um conjunto sistematicamente alimentado pelas totalizações cíclicas; ações concretas que deixam suas marcas, heranças em novelo histórico. Ao buscar as possibilidades de aproximação de diferentes formas de intervenção ou de situações reflexivas (POPPER, 2001; MO-
RIN, 2015; MORAES, 1987) chega-se nas formulações das seguintes questões de partida: Para saber pensar o mundo é premente considerar pertinências que sejam constituídas pela busca de uma consciência verdadeiramente coletiva? E se assim o for, diante de tantas complexidades desse mundo, porque cada linha disciplinar ou campo de conhecimento científico permanece em suas convicções de aprofundamento específico dentro desse universo?

Caso aceitemos compreender que a estrutura do Espaço se organiza pelas divisões de escalas variadas, contidas na totalidade em porções ou partes, dialeticamente interagentes e conformadas por unidades de coerência, três princípios, então, devem ser compreendidos para a fundamentação de uma teoria sobre a divisão espaço:

A Integralidade do Pensamento: Articulação entre os fundamentos das linhas investigativas (campos disciplinares ou estruturas científicas) de cada área de estudo, que sejam atraídas pelas coerências temáticas coexistentes em unidades territoriais que formam o Espaço;

A Inseparabilidade nas Relações do Espaço: Estruturação dos componentes ordenadores do Espaço na constituição de uma rede de relações analíticas que identifiquem as coerências organizacionais dos territórios e suas interações escalares;

A Totalidade das Escalas nas Inter-relações entre as Partes e o Todo: Definição das premissas de recorte de compartimentos territoriais, suas pertinências e coerências na constituição de unidades de manejo reflexivo, assim como na compreensão do movimento das totalidades.

\section{A Formação das Realidades: Movimentos Históricos versus Berço Geográfico}

Diante da ideia de que o universo se constitui de todos os elementos e seus campos de influência, até mesmo das partículas invisíveis e imateriais, busca-se a associação correlacional entre matéria e movimentos em temporalizações relativas. 
Essa condição contribui para a formulação de uma teoria que nos leve a outras formas de aprendizado, de que o Todo é constituído por arranjos, por ordens de influência que se provocam dinamicamente em velocidades variáveis, como que em unidades interagentes, onde a escala é um fator de organização das abrangências por unidades totais.

A divisão de coerências por uma única correlação planetária a partir das possibilidades de compreensão e aceitação do Todo como meio e como princípio, na constituição de formas aproximativas entre as diversidades científicas que ainda caminham erraticamente por vias próprias isoladas, pode estar, intrinsecamente a cada uma, na busca das "chaves de conexão" dentre tantas órbitas dispersivas. Esses elos de aproximação entre interesses disciplinares podem residir na raiz da lógica que agrupa a existência entre os componentes do espaço e suas quintessências.

Elementos materiais e suas amplitudes correlacionais (como campos imateriais de influência), estão em constantes dinâmicas de reciprocidade, pelas abrangências que exercem entre si (em arranjos complexos oscilatórios por amplitudes variáveis), constituindo a estrutura do Espaço.

A questão da totalidade e das porções constitutivas de ambientes formadores das realidades interagentes em territórios intrínsecos ao conjunto dos grandes espaços, é também discutida por Milton Santos. Em seu livro "A Natureza do Espaço - técnica e tempo razão e emoção", de 1996, discute (dentre tantas questões significativas) e aprofunda o significado das forças econômicas e dos processos modificadores do espaço pela diversidade "técnica" como elementos indutores das relações entre os grupos sociais e o meio geográfico. Assim, para o autor, a matriz se dá pela relação entre o homem e o meio - pelo domínio técnico - na constituição produtiva e na formação do espaço, portanto como realização da vida política.

Milton Santos discute, no trecho "O Espaço e a Noção de Totalidade" da referida obra, a relação de dimensão do espaço pela dinâmica dos movimentos que dão ao mundo as totalidades cíclicas (totalização), considerando a pertinência filosófica da noção de totalidade, unidade e dialética "[...] constituindo em elemento fundamental para o conhecimento e análise da realidade" (SANTOS, 1996, p. 93).

O autor retoma ainda a questão aristotélica, questionando sobre a definição de Unidade e da pertinência da totalidade como a soma das partes desprovida de autonomia de cada uma delas no jogo das escalas de correlação com o Universo. Santos (1996) relaciona a compreensão da totalidade como fundamento de compreensão do mundo; do mundo em transformação pelas ações humanas em movimentos que tendem aos ciclos de mudança que regem a dinâmica da realidade. Segundo ele, a escala da totalidade se dá na metamorfose da formação socioeconômica por processos históricos que amplificam a complexidade da vida.

Como, assim, enfrentar a árdua tarefa de entender a totalidade? A primeira noção a levar em conta é a de que o conhecimento pressupõe análise e a segunda noção essencial é a de que a análise pressupõe a divisão (SANTOS, 94. 1996).

Aliando-se ao esforço indagativo de compreensão do mundo está outro importante estudioso da formação dos contextos geográficos brasileiros, Aziz Ab'Sáber. Sua obra é uma fabulosa contribuição ao entendimento das razões fisiográficas do Brasil pela investigação aprofundada da formação dos territórios, sobre a origem da forma e sobre os elementos constitutivos da natureza, os quais, segundo ele, estariam estruturados num "Espaço Total" (MODESI-GALTTIERI, 2010; AB'SÁBER, 1957).

Se para Santos o processo revelador das razões dos territórios encontra a base de investigação nas forças sociais e políticas que disputam tais espaços (e suas amplitudes escalares), pelos modos produtivos econômicos, através da apropriação das técnicas na superação da natureza impondo movimento à dinâmica das totalidades cíclicas (rugosidades); para Ab'Sáber a raiz das realidades está na constatação das relações entre a forma dos ambientes decorrentes de processos sistêmicos e pretéritos relevantes, ori- 
ginados ciclicamente pelas deformações temporais (geológicas) que deram a feição geomorfológica, e que justamente por isso acumulou "resíduos" ecossistêmicos (forma, estrutura vital e desígnios humanos), por onde os seres humanos historicamente buscaram se apropriar.

Essas questões contribuem para a amplificação das definições de Totalidade, de Espaço Total e de Ambiente Total, que permitiria a fusão das relações entre a conformação geográfica e suas abrangências, por estes pensadores e outros que se aproximaram da busca das implicações filosóficas e sociológicas dessa organização desencadeada em escalas de importância para entendimento do universo. Podemos adotar tantas denominações ou conceitos, mas a questão está na compreensão de que o Todo é uma Unidade, mas que as Partes, também, se constituem em Unidades Totais (ARISTÓTELES, 2015).

Essa conceituação é provocada por Santos (1996) quando discute a "cisão da totalidade" pela necessidade de compreensão ampla. Em outra vertente, Ab'Sáber aprofunda a compreensão da compartimentação do espaço geográfico identificando fatores e resquícios paleogeográficos por intermédio da "Teoria dos Redutos" $^{11}$. São duas linhas de aprofundamento que podem ser relacionadas se houver aproximação entre as forças de transformação dos movimentos que formam e são formados pelo espaço e, de outro modo, a decorrência natural pré-existente que prenuncia as transformações que advenham das relações humanas nesse sistemas confinados ou recortados, para os movimentos de persistência da vida.

1 [...] segundo Aziz as Linhas de Pedra e a Teoria dos Redutos são grandes aspectos de seus trabalhos fundamentais" (MODENESI-GAUTMERlet all; 2010). São, segundo ele, a definiçăo geográfica dos climas e as fases climáticas na formação do relevo nacional. "Estendeu questão das Linhas de Pedra para várias outras partes do Brasil, criando a ideia de uma fase fria seca muito ampla Na região equatorial houve mais cerrados e menos matas e na regiáo oriental houve mais caatingas e, igualmente, menos matas. Numa fase posterior dos trabalhos, Aziz percebeu que nem tudo era caatinga na epoca, sobrando redutos de matas, e concluiu que, durante o tempo em que esses blocos de florestas ficaram isolados, a fauna ombrofilica, se refugiou tambem. Houve entáo um processo isolado de ordem genética evolutiva (esse trabalho foi desenvolvido pelo zoologo Paulo Emílio Vanzolini، na Teoria dos Refúgios)" (MODENESI-GAUTTIERI et all; 2010. P. 19).
A compreensão da importância dos fragmentos de estruturas coerentes (forma do relevo, tipos de vegetação, fauna, clima, organizações humanas) obedece a parâmetros científicos de aprofundamento de estudos para compreensão dos porquês, na revelação das razões escondidas pelas quais determinados territórios se mantiveram ou se transformaram significativamente (no caso dos redutos de vegetação e nos refúgios de fauna por resultantes pré-históricas).

Se os redutos e refúgios decorrem de processos de acomodações geológicas evolutivas e gradativamente vão se confinando dinamicamente, pois a vegetação e a fauna se ajustam pelas variações climáticas e pelas conectividades, sua relação com o todo é muito mais dicotômica do que amostral. Mas, por outro lado, ao reconhecer sua importância particularizada pelas condicionantes próprias de sua configuração, o eixo metodológico da pesquisa passa a identificar as razões estruturais de sua existência, invertendo a base de investigação para um sistema que contém contextos surpreendentes e que merecem ser aprofundados de dentro para fora na correlação entre fragmentos da mesma ordem situados esparsamente por territórios distantes, denunciando respostas aos enigmas da maturação da vida. Um sistema que deriva das oscilações e que se mantém ativo, por novas modificações, em amplitudes variáveis, utilizando-se das escalas como parâmetros vitais.

Obviamente que não se aplica às teorias (redutos e refúgios) acima citadas, o mesmo princípio para a fundação de uma Teoria dos Compartimentos a ser constituída, considerando as correlações entre a conformação de sítios e as ocupações humanas mais recentes. Aspectos políticos e culturais de populações humanas que se organizam historicamente em territórios propícios ao assentamento de estruturas coletivas de vida, e que gradualmente vão se tornando cidades para depois superarem suas delimitações locais conectando-se por maiores amplitudes - como um voo cego civilizatório sobre estruturas geográficas ainda não plenamente reveladas -, especialmente pelas dificuldades de equilíbrio entre pensamentos divergentes e acordos pelos melhores processos de maturação da sociabilidade materializada em espaços construí- 
dos, superam a contradição dos fragmentos e reordenam a lógica da transformação por expansão em sistemas sobrepostos.

Três fundamentos podem ser definidos como primeira estrutura composta entre movimentos humanos sobre "berços geográficos", por ações oscilantes na artificialização² dos territórios:

1) A recorrência das correntes humanas como agentes transformadores do meio e das relações sociais e políticas na organização das estruturas de apropriação e desenvolvimento ocupacional;

2) O reconhecimento do significado do "berço geográfico" ou espaço geográfico como suporte e capacidade de apropriação histórica das civilizações e suas interfaces com o meio;

3) A velocidade e o tempo dos processos ocupacionais e exploratórios pelos (e dos) grupos humanos sobre territórios em formação por formas econômicas e técnicas disponíveis.

Transumâncias, "berço" e transformações. A feição geográfica do território, oriunda das alterações pretéritas é um princípio de delimitação do espaço e revela nas ocupações recentes (após seu período de formação geológica) graduais formas de acomodação de grupos humanos em ciclos por sobreposição em camadas, que aliam o domínio ambiental e econômico pelas sucessivas tecnologias que, tanto aprofunda as descobertas do meio como aponta para possibilidades de ação (exploração e assentamentos).

O que temos no Presente é uma definitiva cadeia de organizações sobrepostas, mas em constante adequação, sempre em ciclos de expansão física sobre espaços que tendem ao agrupamento em contiguidades, e ao mesmo tempo, em segmentação por características econômicas e sociais adversas. A totalidade não revela a igualdade, nem a linearidade histórica.

2 Antônio Carlos Diegues em seu livro 0 Mito Moderno da Natureza Intocada, de 1996, aborda os processos de alteração do ambiente chegando a ideia de um suposto ambiente artificial frente a uma suposta natureza original. A discussão aqui tratada estabelece a inter-relação entre tais contextos (natural e artificial) como uma só estrutura sistêmica, capaz de interferir umas nas outras e revelar presença da transformação humana em todas elas, retirando a ideia de Natureza intocada ou espaços isolados, e amplificando a ideia de espaço total ou ambiente total. (DIEGUES, 1996).

\section{A Integridade das Partes: Princípios para o Conceito dos Recortes TerritoriaIs}

O método científico de recortar tecidos ou amostras que sejam significativas - que contenham na particularidade as relações do "todo" - é uma prática. O pressuposto por trás da análise de porções representativas do "todo" é que não se considere a particularidade como um fator de multiplicação por somatória simples, como se o "todo" fosse o agrupamento de uma só amostra repetida. Entende-se que a amostra deve ser um parâmetro de reconhecimento de algo por inteiro quando contém as condicionantes estruturais que a amarram ao sistema geral, mas que podem, por sua vez, conter particularidades únicas que não se rebatem como um padrão.

Ao avaliar e estudar padrões residuais determinados por processos pretéritos que se mantiveram por muitos anos como uma resistente cadeia de lógicas de vida em gradual isolamento cíclico, ou que migraram por canais de sobrevivência alterando conjuntamente sistemas biológicos, gerando outras configurações mais extensas ou mais restritas, pode-se verificar os efeitos dos processos transformadores desses territórios e suas implicações futuras. Ao mesmo tempo, por análise, a busca de respostas científicas em fragmentos representativos demonstra firmemente práticas aceitas como corretas na condução de processos de investigação e pesquisa - de caráter rigoroso e científico. Assim sendo, não se aceitaria a normativa de insulamento de fragmentos ou recortes extraídos de certas estruturas maiores, como únicas constatações por conteúdo específico rebatendo meramente para o "todo", mas ao contrário disso, a metodologia de extrair para verificar as relações entre a "parte" (amostral) e o "todo", devolvendo o que é de interesse estrutural para o "todo" e aprofundando aspectos específicos mais intrigantes nas "partes" como universos particularmente próprios.

Casos extremos que representam inéditas constatações, como em certos fragmentos soltos em sistemas diversos e determinantes, são objetos de análise que carregam consigo a unicidade dos conteúdos. Entretanto, as suas correlações periféricas com vetores de 
articulação entre o fragmento e a totalidade de territórios que o cerca, quando a conformação lhe dá uma célula de coerência em meio a um oceano de coerências constituídas por outras lógicas de vida, podem se dar como linha claramente demarcada, em confronto de fronteiras entre universos diretamente conflitantes.

As discussões sobre a necessidade de aproximação dos contextos de interesse se apoiam em outros recortes na figura das Unidades de Estudos, Unidades de Paisagem ou de Interesse (SILVA, 2013). A própria forma de recortar territórios para seu entendimento mais amplo e detalhado, assim como para sua reconstituição e junção operativa das ações que interferem em escalas de complementariedade, é uma prática do planejamento (zoneamentos, macrozoneamentos, setorizações, unidades de planejamento, etc.) e das ações de prospecção de problemas e potencialidades, adotadas por diversas áreas de conhecimento.

A geógrafa Cleide Rodrigues (2005), em seu trabalho de análise das correlações entre unidades morfológicas físico-territoriais e morfologias antropogênicas, procura estabelecer a analogia entre morfologias (originais e alteradas por processos humanos) para definição de unidades espaciais de planejamento, tendo como estudo de caso a metrópole paulista.

Dentre as inúmeras contribuições desse trabalho, a questão das interfaces entre estruturas morfológicas recortadas como áreas de estudo e aprofundamento geomorfológico, que agrega as implicações antrópicas em suas alterações físicas como uma fusão unitária de fatores que dão ao recorte a sua configuração própria, numa espécie de identidade geográfica integrada, incorpora no estudo geral a condicionante da forma do território e suas feições pela sobreposição de forças que delineiam uma outra maneira de considerar limites para estudos mais precisos: a morfodinâmica.

A diferença fundamental para outras abordagens é a consideração da própria interferência antrópica como ação geomorfológica, ação essa que pode: modificar propriedades e localização dos materiais superficiais; interferir em vetores, taxas e balanços dos processos e gerar, de forma direta e indireta, outra morfologia, aqui denominada de morfologia antropogênica. (RODRIGUES, p. 101. 2005)

Esse conceito se aproxima das investigações da paisagem como resultado vivo das relações humanas em constante modificação, alterando a estrutura original natural que antecede ao processo de ocupação. Ao invés de substituir a paisagem natural pela paisagem artificial (social, econômica, política e cultural), compreende-se que a presença humana aprende em diálogo ríspido que se traduz nas novas configurações, constantemente alimentadas pela história.

Em Gregotti (1972), a disciplina do espaço pela dimensão da paisagem buscando a relação entre a Arquitetura e seu todo contextual, aparece como uma tentativa de extrapolar os domínios do objeto pelas eventuais conexões que haja entre objetos arquitetônicos num "todo" transformado pelas mãos humanas. Ao se referir a Antropogeografia, nos domínios da Geografia, Gregotti enfatiza a qualidade de seu foco de análise.

É necessário, contudo, identificar os limites desta área, para estabelecer uma coordenação entre os diversos estudos, mas também para determinar qual seja o campo próprio e específico da arquitetura como ambiente total e diferenciado da geografia científica. (GREGOTTI, p. 63. 1972)

A base do pensamento que une as relações humanas à geomorfologia, constituiria um novo termo - cunhado pelo alemão Friedrich Ratzel (1844/1904) - e desenvolvido por outros autores (com diferentes visões críticas, especialmente quanto à linha "determinista" de Ratzel) que é a "antropogeografia" (Anthopogeographie) (DANTAS e MEDEIROS, 2008) ou, dialogando com RODRIGUES (2005), uma "antropogeomorfologia" (GOMES, 2005) $)^{3}$.

Retomemos a questão da divisão do Todo para conhecimento das Partes, dialeticamente impulsionando para a possibilidade plena

3 http://www.vitruvius.com.br/revistas/read/entrevista/06.023/3315 
e complexa da compreensão do Todo a partir do conhecimento das Partes. Uma experimental desconstrução da totalidade pela dialética das escalas. Essa estratégia de apropriação das realidades que interagem no mundo, pressupõe que a necessidade de responder aos mistérios da associação entre o espaço físico e o espaço social, como um processo vivo e mutante pela amálgama histórica, ora tendente ao conflito ambiental ora ao conflito político e econômico, e que em sua cíclica movimentação resulta em intermitentes realidades, dá à totalidade um tempo que a consolida transitoriamente (SILVA, 2016).

Ainda assim, não há consenso técnico e conceitual de que a divisão dos ambientes e das temáticas em porções de aprofundamento teórico e operativo, permite uma maior proximidade dos elementos compositivos dessa ordem analítica.

O que se pretende com essa reflexão é dar ao "método do recorte" uma outra possibilidade dinâmica, onde a delimitação das partes, por associações analíticas (suporte ambiental, ambiente transformado e estrutura socioambiental), seja complementada por outras variáveis de reconhecimento e condução técnica de resultados. Como um desafio às verdades, pode-se não considerar que a fragmentação do espaço tão somente e as formas de compreendê-lo por aproximação em subdivisões (como prática usua no tratamento do projeto, do plano e dos programas técnicos), atenda as prerrogativas de pulsação das necessidades que nele existam, mesmo na proximidade dos problemas detectados das Partes recortadas de um Todo.

Isso infere na forma como se elegem os limites físicos ou sociopolíticos (linhas ou manchas) que são adotados formalmente como legítimas delimitações de conteúdo das porções de interesse convencionalmente aceitos. Como certos trabalhos efetuam leituras territoriais considerando amplitudes muito maiores que a própria definição de área de ação ${ }^{4}$, a delimitação dos recortes de aproximação obedece a parâmetros e acordos que

4 Ver os casos das Áreas de Influência dos Estudos de Impacto Ambiental EIA RIMA, das experiencias de planejamento territorial em áreas de reserva (Planos de Manejo de Parques e em Areas de Proteção Ambiental), ou nos Planos Diretores Municipais ou Metropolitanos - pela adoção das Macrozonas e das Macroáreas. muitas vezes são pactos políticos ou culturais assumidos nos contextos dos estudos.

A forma de aproximação decorre das leituras e construção tática das verificações do âmbito geral do trabalho (que dá a definição dos limites do plano ou da ação pretendida), portanto, derivando das grandes escalas - por processos de levantamentos e modalidades de planejamento - na configuração das estruturas determinantes do suporte territorial estudado e suas derivações até a demarcação dos setores ou fragmentos de interesse.

Essas "linhas de fronteiras", usualmente estabelecidas, se baseiam em barreiras ou transições verificadas no meio, e também em conformações históricas e administrativas, buscando revelações de coerência em seu conteúdo recortado pela aceitação convencional, mas necessitam ser repensadas pela extensão das abrangências ambientais e pelas movimentações pendulares que transcendem tais regulações. Tomemos o exemplo de um córrego hipotético pertencente a uma bacia hidrográfica que ao invés de ser considerado a "espinha dorsal" na estrutura ambiental do contexto a ser compreendido para ser planejado, é tratado, quase sempre, como elemento delimitador entre porções; ou seja, se perde a sua pertinência territorial sendo reduzido a uma mera linha divisória.

As ações técnicas operacionais obedecem demais, por assim dizer, ao pressuposto estático das amarrações legais ou das determinações políticas isolando-se das devolutivas públicas que deveriam prevalecer como princípio dinâmico, informando claramente aos segmentos da sociedade a forma de reconhecimento do território e as razões de sua ação.

Parece haver uma dissintonia entre o que realmente ocorre e infere nas razões da paisagem que se transforma velozmente pelas variações econômicas e sociais, e aquilo que os padrões e procedimentos institucionais de leitura e operação pública praticam, através da legislação, nas condutas e nos instrumentos de planejamento (controle e "desenvolvimento" urbano e rural). A defasagem está na compreensão do território e das estratégias econômicas tais como são, como a única realidade, uma espé- 
cie de decorrência natural, que, ao ser analisada revela somente os contornos de sua essência, esconde as rugosidades (SANTOS, 1996) e as anomalias de futuro.

Nesse sentido, se pode entender que a revelação da realidade e suas amplitudes e dissimulações públicas, esteja no desvelamento dos "filtros" do território por meios da constatação das matrizes ambientais e suas conformações políticas, ordenadas por outras lógicas organizacionais pouco questionadas.

Essa questão está atrelada à possibilidade de compreender as realidades por aproximação, sem necessariamente destacar decisivamente (e definitivamente) a porção do Todo, pois se entende que o espaço, portanto, não se divide, mas se volatiliza nas relações entre os objetos e as suas órbitas de correlações organizacionais distribuídas pela lógica das totalidades interdimensionais.

Inicialmente, é fundamental determinar o âmbito da problematização. Considera-se, na leitura das realidades fundantes da indagação, o conceito de conteúdo espacial, ou o que poderemos tratar por "unidade de coerências", sistêmicas em ambientes divisíveis (mas, inter-relacionados). Esse arranjo de forças correlacionadas em determinados contextos é a matriz da investigação; ou seja, a válvula que dispara a sua pertinência como relevante temática no desenvolvimento dos caminhos da pesquisa a ser compartilhada.

Trata-se da constituição de estrutura dialética que permita, a partir da sua aplicabilidade sistêmica (transição entre conteúdos e âmbitos), identificar os componentes espaciais e suas escalas de importância como pano de fundo da análise e seus desdobramentos pela "pendularidade dos contrários", no sentido de qualificar as formas de leitura e de reconhecimento das realidades vigentes em territórios objeto de estudos. Dessa maneira, a possibilidade de amplificação das formas de leitura das realidades (processos históricos de apropriação de determinados territórios e suas conformações ambientais) se baseia na transição entre os vetores de força vital que interagem nesses ambientes recortáveis por razões identificáveis (físico, biótico e antrópico, simultanea- mente convergentes), que podem definir limites ou perímetros de delimitação de unidades.

São as coerências que dão a totalidade das partes que integram, onde se lê claramente a sua configuração fenomenológica, decifrando as razões de sua trajetória histórica no desvelamento dos movimentos contemporâneos.

Entende-se, desde já, que a divisa das partes de um determinado espaço não seja compreendida como uma barreira ou cisão fortemente demarcada a ponto de romper inexoravelmente entre os dois lados cindidos. A linha divisória ou linha de recorte entre duas partes, ou mais, de um compartimento decorre da análise inter-relacionada entre as pertinências e as continências desses contextos a serem partidos, definidos após minuciosa combinação entre os elementos estruturadores dessas unidades, e que emprestam totalidade a essas partes.

Esse ordenamento dos conteúdos por importância e significado no contexto geral de territórios de interesse, além das possibilidades de delimitação de cada âmbito de conectividade, não isola ou congela cada porção em uma intra territorialidade, como se nota em diversos trabalhos técnicos de planejamento ou em estudos de impacto ambiental ${ }^{5}$ (ambos por determinação legal), por exemplo, mas garante uma pulsação nas trocas das ambivalências relacionais entre os fatores de organicidade do meio que têm ligações variadas em distâncias variadas.

Considerando essa conceituação, a divisão entre as partes não pode estabelecer a ruptura para o detalhamento específico de cada uma. A noção da definição do recorte por esse conceito, permite operar a unidade de coerência e sua interligação com unidades variáveis, articuladoras das "coerências integradas".

Sobre a compreensão das "coerências integradas", ou o que podemos definir como sendo uma "tese da integralidade", há a ne-

5 Ver o Caderno Anexo Único - Art.1 da Decisão de Diretoria № 217/2014/1, de 06/08/2014, elaborado e aprovado pela Companhia Ambiental do Estado de São Paulo CETESB. Esse caderno integra o Manual para Elaboração de Estudos para o Licenciamento com Avaliação Ambiental, que aborda entre tantos, aspectos de subsídio ao processo de elaboração de Estudos de Impacto Ambiental ElA e seu respectivo Relatório de Impacto Ambiental RIMA. Capítulo 5 - Áreas de Influência, p. 99-103. 
cessidade de organização técnica de métodos de reconhecimento territorial a partir da prospecção de matrizes disciplinares em grades analíticas que decorrem das leituras (de compartimentos a serem delimitados ou já delimitados) territoriais que obedecem a três campos específicos e sobrepostos:

a) Sistema de Elementos Estáticos: considerando a necessidade de compreensão das estruturas físicas e bióticas que conformam o "berço geográfico", ou o suporte da Paisagem - geomorfologia, coberturas de vegetação (natural e agrícola), estrutura climática, estruturas geológicas (aquíferos), estruturas de ocupação fixas e linearidades (viários, sistemas de logística), equipamentos estruturais de grande porte;

b) Sistema de Elementos Dinâmicos: considerando a necessidade de compreensão das estruturas bióticas e antrópicas, ou as tramas vivas que coabitam nas conformações dos compartimentos dos suportes físicos estáticos - mobilidades, intensidades de fluxos, usos e formas de ocupação urbana e não urbana, estrutura socioeconômica, estruturas culturais, variáveis políticas administrativas, conectividades faunísticas, processos históricos;

c) Sistema dos Elementos e Contextos em Conflitos: considerando a necessidade de compreensão das rupturas decorrentes das transições entre fixos e dinâmicos, ou das tensões entre grupos humanos e ou entre esses e as condicionantes bióticas e a paisagem - detecção dos pontos ou estruturas que apresentam potencial conflito ambiental ou socioeconômico (ou ambos simultaneamente verificados), capacidades de sustentação, impactos de diferentes ordens, rupturas ou divergências temáticas ou relacionais.

A leitura das matrizes e seus devidos cruzamentos interativos, permite o delineamento das estruturas significativas do território tanto para a definição da maior escala ou o que podemos denominar como a maior delimitação territorial para um estudo ou ação técnica, como para as escalas subsequentes de aproximação de acordo com as prerrogativas que o trabalho assim exigir. A delimitação de uma grande escala ${ }^{6}$ decorre do cruzamento das

6 Por convenção adotaremos a denominação de "grande escala" para a primeira e maior entre as escalas de recorte de interesses para qualquer estudo ou processos de projetaçáo, informações e verificações dos territórios e suas amplitudes de domínio (Estruturas Físicas, Bióticas e Humanas) resultando naquilo que poderemos denominar de primeiro campo de conhecimento integrado (conteúdo e inter-relações). Essa dimensão primordial pressupõe a maior unidade construída como referência de operação dialética, onde a linha divisória (como interlocução entre o que está dentro e o que está fora), consagra a unidade coesa entre universos de aproximação. O que está fora desse recorte se transforma num conjunto de parâmetros de diálogo e de inferência, como que parametrizando ou ponderando a base das perguntas. Se pudermos assim estabelecer, diríamos que o universo externo ao recorte da maior escala, estabelecida pela análise inicial, se comporta como uma Antítese que baliza as escolhas pelos percursos que se darão no universo interno do mesmo recorte.

A mesma prática aplicativa das matrizes pode ser continuada no processo de pormenorização dos conteúdos de unidades de estudo, cada qual considerando o conjunto de coerências que as compõe, tendendo cada vez mais para as particularidades. Esse exercício de recortes desdobrados e interagentes propicia a lógica da integralidade aliada à inseparabilidade, fortalecendo as totalidades unitárias e as suas correlações com a "grande escala", e entre esta e o Todo, traduzida como a mecânica entre as totalizações. O conceito da linha divisória não é a cisão, mas a noção de diálogo pela evidência das particularidades coesas.

Os pontos de interesse ou as linhas de delimitação dos recortes são obtidos pelas sucessivas sobreposições de informações mapeadas e reconhecidas no território e suas variáveis de escala. A constatação dos marcos que irão compor a linha demarcatória das divisas do compartimento de interesse, decorre das simulações e definições dos elementos físicos e ambientais, aliados aos vetores econômicos e históricos, considerando seu conteúdo uniou planejamento, que seja eleita pela lógica dialética entre os diferentes sistemas do espaço, manejadas pelo operador. Essa dialética de idas e vindas entre escalas continentes, ora intrinsecamente aprofundadas, ora transcendentemente balizadas, se ancora nas conexões coerentes entre a dualidade da leitura e os passos de desenvolvimento da proposta. Desde já, fica a conceituação de: a maior escala desejada para o início de um processo de interação com o meio para diferentes formas de ação, podendo variar, quando se elege, desde apenas uma quadra urbana, até mesmo uma rota interplanetária. 
forme ou heterogêneo, em camadas de constatação e negação, alimentando o processo dialético das probabilidades de resultados até a confirmação de um desenho síntese.

Importante mencionar que essa prática se aplica a duas condicionantes reflexivas estruturadoras do campo da Arquitetura e do Urbanismo, que este estudo quer contemplar: a) aplicabilidade dos instrumentos de planejamento e projetos (ou ações programáticas territoriais) para a compreensão e operação técnica em territórios de grande escala e seus desdobramentos; b) aplicabilidade dos processos dialéticos de consolidação de projetos e suas amarrações escalares ou em projetos a serem revelados em territórios de interesse, por processos aproximativos e confirmatórios (programa e conformação arquitetônica).

Algumas ações no campo do planejamento e nas avaliações de impacto ambiental já estão ditando as normativas legais de aprovação e gestão, mas merecem um olhar mais cuidadoso.

A determinação dos organismos ambientais governamentais que formatam e gerem processos de aprovação e licenciamento ambiental no estado de São Paulo, segundo normativas legais estaduais e federais, estabelece regulações de elaboração e acompanhamento dos Estudos de Impacto Ambiental EIA e seus respectivos Relatórios de Impacto Ambiental RIMA. Uma etapa importante desse estudo é a definição dos recortes de delimitação de áreas de influência (três âmbitos de influência compõem os estudos ambientais ${ }^{7}$ ), que devem conter em cada abrangência o reconhecimento dos componentes ambientais que podem sofrer, pela ordem de amplitudes, os impactos relativos ao empreendimento avaliado em questão. Os recortes para estudos dos territórios levando em conta as suas prerrogativas de reconhecimento de suporte para a correlação

7 Três áreas de interesse por amplitudes compõem a linha de análise de territórios que são submetidos à potenciais impactos decorrentes dos projetos influentes no meio ambiente, saber: ADA Area Diretamente Afetada - ou aquela que está diretamente ligada às açôes de impacto direto do empreendimento, ou seja em sua área de inserção; AID Área de Influência Direta - ou aquela que recebe a partir da area diretamente afetada as influencias do impactos do empreendimento num recorte maior e; All Area de Influência Indireta - ou aquela que pode receber impactos derivados das outras duas áreas de influência conforme a sua abrangência no território, extrapolando as fronteiras da intervenção. entre objeto com potencial de impacto, bem como a avaliação de formas de mitigação ou compensação desses impactos para fins de aprovação legal e sua execução, são fundamentais para verificar as abrangências e seus conteúdos, e determinar após essa compreensão ou "diagnóstico", fatores dimensionáveis para corrigir eventuais danos ao meio ambiente nos preceitos da lei do "rito" de avaliação e do licenciamento.

A metodologia de recortes das Áreas de Influência para Estudos de Impacto Ambiental, é determinação legal e componente das normativas que regulam os documentos de análise e aprovação, portanto, tem relevante papel nesse processo de leitura e avaliação do meio e sua consequente alteração. Entretanto, nem os critérios que elegiam as prerrogativas de escolha de seus âmbitos de recorte entre os anos de 1980 até 2014 (ano que em que se deu a constituição de novos parâmetros institucionais), e nem após as determinações das novas regras de aprovação e licenciamento - que devem integrar rigorosamente o conteúdo e formato dos EIA RIMA na atualidade -, apontam para processos que sejam realmente essenciais e indiscutíveis a luz dessas delimitações técnicas de influência dessas áreas.

Essa vertente, qual seja, a de descrença no planejamento, especialmente nos planos urbanísticos (Planos Diretores Municipais e suas formas operativas e políticas) tem sido, nos últimos anos, uma linha crítica de vários autores (VILLAÇA, 1999) ${ }^{8}$ - arquitetos e urbanistas - e também de grupos políticos que veem na gestão do território uma abertura para a dissimulação das ações que poderiam dialogar com os diferentes moradores como ferramenta democrática e amplificadora das possibilidades de emancipação da sociedade pela leitura clara de seu espaço, especialmente na possibilidade de desdobramentos de apropriação desses meios e dos mecanismos políticos operacionais de indução de novas ações, configurando concreta relação de disputa e, quem sabe um dia, de equilíbrio entre fatores tão distintos e oponentes. Aprender a ler o território diante de suas riquezas e multiplicidades pode ser uma possibilidade de revelação ao conjunto da

8 In DEAK, C; SCHIFFER, S. R. (org.) O Processo de Urbanização no Brasil. Edit. Universidade de São Paulo. São Paulo, 1999. 
sociedade da realidade coletiva, ingrediente fundamental para a apropriação do território como conteúdo político.

Arquitetura e Urbanismo se aproximam, enfim, como um campo único, estabelecendo múltiplas variações e multipolaridades de produção e fundamentação teórica.

\section{CONSIDERAÇõES FINAIS}

O presente trabalho problematiza a divisão do espaço que não deve ser compreendida aqui como particularização dos fragmentos ou segmentos de tamanho e conteúdo. Por outro lado a necessidade de reconhecer a estrutura do espaço como indivisível pela integralidade dos campos de conhecimento, ainda que pulverizados em suas coerências próprias e intrínsecas, obriga à pesquisadores a apontar para a confluência de amarrações interdisciplinares cada vez mais evidentes. Nesse sentido a totalidade é a questão a ser tratada, mas não é o "grilhão" que aprisiona a linha decisória da reflexão.

Entretanto, a noção de totalidade, que em nosso caso ampara sobremaneira a tese da coesão do espaço, retoma a ideia das totalizações sequentes nas maturações temporais sucessivas e complementares (mesmo pelas dissonâncias históricas), dando ao método a possibilidade de partir trechos que contenham e carreguem consigo a força do Todo pela detecção dos registros peculiares.

Para este trabalho a subdivisão do espaço deve obedecer a princípios que aproximam a variação das ações do arquiteto e urbanista para com o objeto e a escala de abrangência desse objeto ou, ainda mais, entre o sentido dos lugares e suas correlações de amplitudes, englobando os problemas das ações humanas materializadas ou não no espaço (história imaterial).

Além do artigo buscar contribuir para a discussão teórica de diferentes campos científicos a discussão metodológica colabora na problematização referente às definições de critérios no estabelecimento das Áreas de Influência para Estudos de Impacto Ambiental, que apesar de terem determinação legal de aprovação e licenciamento e componente das normativas que regulam os documentos de aprovação seguem com fragilidades no estabelecimento de seus limites.

A proposta metodológica de subdivisão do espaço não se concentra nas decisões temáticas em confinamento (coerências monotemáticas), mas no cruzamento das temáticas do espaço definidas pelas coerências articuladas em sistemas de troca vitais (coerências pluritemáticas).

\section{RefERÊnCIAS BibliográficAs}

AB'SÁBER, Aziz Nacib. O sítio urbano de São Paulo. In: Aroldo de Azevedo (org.). A cidade de São Paulo: estudo de geografia urbana. São Paulo: Companhia Editora Nacional p.169-243, 1957. (Coleção Brasiliana, vol.14)

ARISTÓTELES. Metafísica. São Paulo: Edipro, 2015.

DANTAS, Aldo; MEDEIROS, Tásia H. L. Geografia Ratzeliana e seu contexto. Braślia: Programa Universidade a Distância UNIDIS Grad/Ministério da Educação/SEED, 2008. (Colaboram diretamente nesse estudo a Universidade Federal do Rio Grande do Norte UFRN, e Universidade Estadual da Paraíba UEPB)

DIEGUES, Antônio Carlos. O mito moderno da natureza intocada. São Paulo: HUCITEC 1996.

GOMES, José C. Entrevista: Retto Junior, A.S., Constantino, N. R. T., Enokibara, M. Revista Vitruvius, 2005.

GREGOTTI, Vittorio. Território da arquitetura. São Paulo: Perspectiva, 1972.

MODESI-GALTTIERI, May C. [et al.] (org.) A obra de Aziz Nacib Ab'Sáber. São Paulo: Beca Ball, 2010.

MORAES, Antônio Carlos R.; COSTA, Wanderley M. Geografia crítica: a valorização do espaço. 2. ed. São Paulo: Hucitec, 1987

MORIN, Edgar. Introdução ao pensamento complexo. trad. Eliane Lisboa. 5. ed. Porto Alegre: Sulina, 2015.

MORIN, Edgar. Os sete saberes necessários à educação do futuro. São Paulo: Cortez; Brasília, DF: UNESCO, 2000

POPPER, Karl. R. A lógica da pesquisa cientifica. São Paulo: Cultrix, 2001.

RODRIGUES, Cleide. Morfologia original e morfologia antropogênica na definição de Unidaes Espaciais de Planejamento: exemplo na metrópole paulista. Revista do departamento de

SANTOS, Milton. A natureza do espaço: técnica e tempo. razão e emoção. São Paulo: HUClTEC, 1996

SARTRE, Jean Paul. Search for a method (196). New York: A Vintage Book, 1968 
SILVA, Jonathas Magalhães Pereira da; MANETTI, Claudio; TANGARI, Vera. Compartimentos e unidades de paisagem: método de leitura da paisagem aplicado à linha férrea. Paisagem

SILVA, Jonathas Magalhães Pereira da. Para que serve a morfologia urbana. Revista de Morfologia Urbana. Revista da Rede Lusófona de Morfologia Urbana. v. 4, n. 2; p 119-121, 2016.

SILVA, Jonathas Magalhães Pereira da. As unidades de paisagem como método de análise da forna urbana: re

VILLAÇA, Flávio. O processo de urbanização no Brasil. In DEAK, C.; SCHIFFER, S. R. (org.).O processo de urbanização do Brasil. São Paulo: EDUSP, 1999.

WHITEHEAD, Alfred North. An enquiry concerning the principles of natural knowledge. Cambridge, Mass: Cambridge University Press 1919.

Claudio Manetti

Pontifícia Universidade Católica de Campinas PUC-Campinas, Faculdade de Arquitetura Urbanismo

m 136, s/n, Rod. Dom Pedro I - Parque das Universidades, Campinas - SP, 13086-900

CV: http://lattes.cnpq.br/9757392947811691

34 Orcid: https://orcid.org/0000-0002-6394-1276

claudiomanetti@uol.com.br.

Jonathas Magalhães Pereira da Silva

Pontifícia Universidade Católica de Campinas, PUC-Campinas, Faculdade de Arquitetura Urbanismo

m 136, s/n, Rod. Dom Pedro I - Parque das Universidades, Campinas - SP

13086-900

CV: http://lattes.cnpq.br/8639950603854048

Orcid: https://orcid.org/0000-0002-8186-9626

jonathas.silva@puc-campinas.edu.br.

Nota do Editor:

Revisão do texto: Autores

Aprovado em: 11/03/2019 